\title{
Conferences/Seminars
}

\section{Summary Report of the Round Table on Problems of Professional Translation in the Arab/Muslim World and the Contribution of Technology}

\author{
Tangier, Morocco \\ Shawwä 26-2\&, 1409/June 1-3, 1989
}

Under the sponsorship of the International Federation of Translators (FIT) and the U.N. Educational, Scientific, and Cultural Organization (UNESCO), a Round Table on the Problems of Professional Translation in the Arab World and the Contribution of Technology was held from June 1 to 3,1989 at the King Fahd Advanced School for Translation in Tangier, Morocco. This was a successful meeting both because of the number and the quality of participants, all of whom were professionals and specialists in translation, terminologists and machine translation researchers from European and Arab countries.

It was a unique occurrence of its kind, as President of FIT Mme Anna Lilova pointed out in the opening session, because it is the first time that the Federation has organized such a meeting in an Arab country. Presentations dealt with three main topics, a day being devoted to each: (1) the status of the translator in the Arab countries; (2) the translator and MAT (machineassisted translation); and (3) terminology work in the Arab countries.

In Arab countries translation is a tradition going back to the Abbasids, but even today it still does not have specific guidelines. Mr. Amid from UNESCO stressed the need for legislation, with the help of translation institutions, which would protect the rights of the translator. Mr. Rene Haeseryn, Secretary-General of FIT, in his presentation on "The FIT and its Main Role in the World Translation Movement," pointed out the humanist goals of the Federation and its role in the protection of translators' rights. "We should protect the translators' rights, but also prepare him for the main choices of the future" was the primary concern which emerged from these working meetings.

"Translation is a profession which presupposes training according to a well-thought out methodology" was the theme of various comtributions from the floor. Therefore, we should develop appropriate training suited to the needs and harmonize it in the various Arab countries.

Also, thanks to new technology, the profession of translation is now seeing its image change. The presentation by Veronica Lawson (FIT) of various systems (machine translation with or without human assistance) enabled us to gauge the progress made. But is the translator of Arabic ready to take up the challenge of machine translation? 
Sami Trabulsi, Advisory Engineer of the Team from Morocco, pointed out that although many projects are under way (in Damascus, voice synthesis; in Egypt, a project for complete analysis of the Arabic language; in Kuwait, re-accentuation of Arabic words), few of them had gotten beyond the planning stage for lack of funding. There is no secret to it: where there is funding, there has been progress; to wit, Japan occupies a leading position in the world market today.

The third day, devoted to terminology, brought out the absence of standardization in this field. Efforts by the IERA (the Study and Research Institute for Arabization in Rabat, Morocco) have made an important contribution, but the IERA's work has not been widely disseminated. We should, therefore, as the participants recommended at the end of this round table, step up our efforts for unifying terminology throughout the Arab world.

Harmonization, concerted effort, and defense of the translator were the key words of this meeting.

Samia Berrada

King Fahd Advanced Translation School Tangier, Morocco

Courtesy of Jerome Quarterly, Vol. 5:1 